\title{
Institutions for collaboration in industrial clusters: proposal of a performance and change management model
}

\author{
Carpinetti, Luiz C. R., \& Lima, Rafael H. P. \\ Department of Production Engineering - University of Sao Paulo (USP). \\ Av. Trabalhador São-carlense, 400, São Carlos-SP - Brazil. \\ carpinet@sc.usp.br \\ rhlima@sc.usp.br
}

\begin{abstract}
This paper proposes a performance and change management model for institutions for collaboration (IFCS) in industrial clusters to assist them while planning, conducting and evaluating joint actions. A three-stage implementation scheme and a self-assessment tool that helps an IFC determine its compliance with the proposed model are also introduced. The self-assessment tool was applied in three Brazilian IFCs from different clusters. It was found that the IFCs researched face major difficulties in designing and implementing performance measures to evaluate the results and impacts of joint actions. However, IFCs have been successful in identifying local infrastructure and devising informal strategic plans.
\end{abstract}

Key words: industrial clusters, performance management, collaborative networks, institutions for collaboration.

\section{Introduction}

Geographic agglomerations of firms have been widely studied in the literature and are often referred to as industrial clusters. The topic has become top priority in the agenda of many regional development agencies and national governments, especially due to the competitive advantages and economic development they enable to firms and to the regions they are located (Porter, 1998; Mytelka and Farinelli, 2000; Sölvell et al., 2003). Companies located in these regions can benefit greatly from external economies, collaboration, and exchange of knowledge between organizations (Unido, 2001; Karaev et al., 2007; Capo-Vicedo et al., 2008). Such benefits may be extended if firms act together through joint actions that stimulate them to collaborate for the common good (Bititci et al., 2004). However, some authors argue that the execution of joint actions requires some sort of local coordination, whose role is to intermediate the interests of companies and coordinate the execution of activities related to the joint action (Schmitz and Nadvi, 1999; Sölvell et al, 2003; Gerolamo et al., 2008).

The definitions found in the literature for industrial clusters often emphasize the importance of related institutions that do not participate directly in the supply chain, but are fundamental for the cluster activities (Porter, 1998). Examples of such institutions are universities, research centres, training centres and specialized service providers. Karaev et al. (2007) highlights the existence of local supporting institutions that are oriented to the particular needs of the cluster participants. In Brazil it is common to observe local associations that promote initiatives that seek to satisfy some needs common to a subset of the local firms. Some authors have reported on cases of such institutions, such as Schmitz (1998), Sölvell et al. (2003) and Gerolamo et al. (2008). The term institution for collaboration (IFC) is used in this paper to refer to such supporting associations.

This paper studies how IFCs manage joint actions in industrial clusters. For this purpose, a performance and change management model is proposed to guide such institutions in the conduction of joint actions. The model is strongly influenced by the PDCA cycle and continuous improvement principles. The model outlines a series of performance and change management practices to assist IFCs in the planning, implementation and assessment of joint actions. Therefore, the model stresses the importance of performance measurement systems as a way of demonstrating the benefits gained through joint 
actions. Later on the model is organized in three implementation stages and a self-assessment tool is devised to evaluate the institution's management practices. The self-assessment tool was used to evaluate the management practices of three Brazilian IFCs from different industrial clusters Sertaozinho (metal-mechanic cluster), Arapongas (furniture cluster) and Londrina (information and communication technology cluster).

The article is organized as follows: Section 2 describes the research method and Section 3 presents the theoretical background used to support the management model. Section 4 introduces the performance and change management model, the implementation stages and the self-assessment tool. Section 5 describes the application of the selfassessment tool in the three IFCs, whilst Section 6 discusses the data collected. Finally, Section 7 concludes the paper by summarizing the findings and suggesting topics for future research.

\section{Research method}

Figure 1 shows the procedure adopted in this research. Given the objective of this paper, it was deemed necessary to review the literature on industrial clusters, performance management in industrial clusters, and institutions for collaboration. The knowledge gained during this activity served as background for the proposition of the performance and change management model. After that, three implementation stages and a self-assessment tool were derived from the management model. This tool aims to quantify the extent to which an IFC complies with the model, that is, it points what management practices outlined in the model the institution has or has not implemented. The self-assessment tool, which is described in detail in Section 4, consists of 18 requirements derived from the management model. A supporting question was associated to each of the requirements, so that the person conducting the assessment understands what should be assessed in a given requirement. During the self-assessment, a score ranging from 0 to 10 is associated to each requirement indicating the level of compliance of the IFC with the management model. The scores obtained are then grouped according to the implementation stages to which they are associated to determine the areas that need improvement with respect to the institution's management practices.

The items listed in the theoretical contribution served as guidance during the self-assessment carried out in the three cases, which were based on interviews

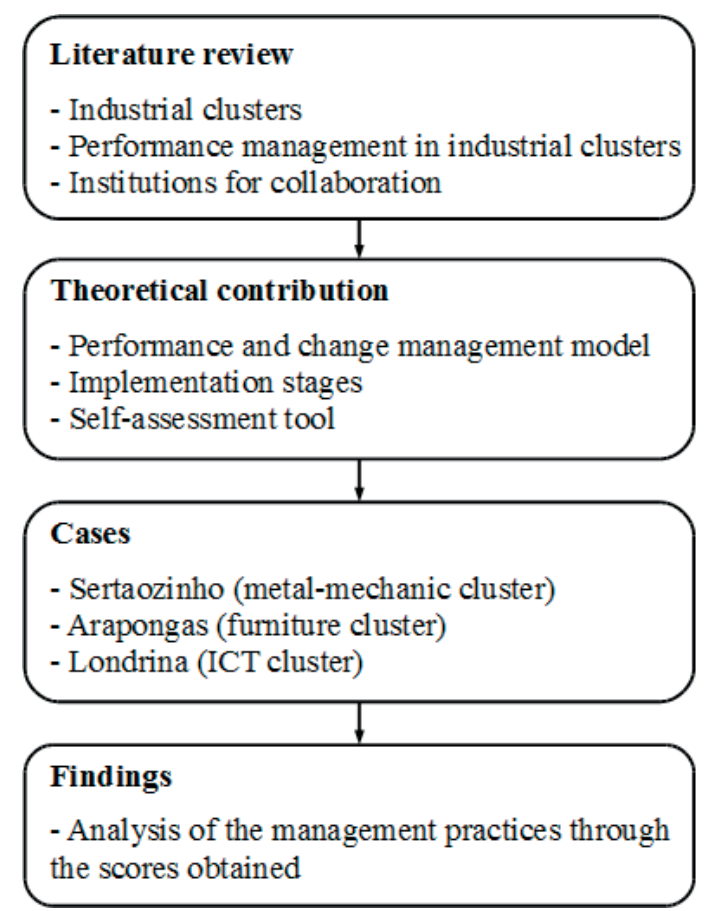

Figure 1. Research method.

with the coordinators of each institution. One of the authors acted as a facilitator during the application of the self-assessment tool and in the determination of the scores to each requirement. The answers given by the coordinator were transcribed and qualitatively evaluated to determine such scores. The scores were then arranged in a table, in such a way to enable a cross-case analysis. The findings were based upon the comparison of similarities and differences between the cases.

\section{Literature review}

\subsection{Industrial clusters}

The term industrial cluster was made popular in the late nineties by Porter (1998), who defined it as geographic concentrations of interconnected companies and institutions in a particular field. His definition also encompasses other entities that are important to competition, such as suppliers of specialized inputs, service providers, specialized infrastructure, and governmental and private institutions as universities, training providers or trade associations. In Brazil the government, funding institutions and some research centres refer to industrial clusters by the acronym APL, which stands for local productive arrangements, as defined 
by the Brazilian Ministry for Development, Industry and Foreign Trade (MDIC, 2010).

The fundamentals that seek to explain the competitive advantages of industrial clusters were set out in the 19th century by Alfred Marshal, who noted that geographical agglomerations of firms might ultimately result in three types of externalities - pool of specialized workers, specialized providers of inputs and services, and the technological spillovers that flow easily among co-located firms (Krugman, 1991; Plummer and Taylor, 2001; Cortright, 2006). These externalities are called by Marshal as external economies. Schmitz and Nadvi (1999) added that, aside of the unplanned benefits of external economies, companies in industrial clusters may gain competitive advantage through planned joint actions, which are enabled by cooperation and collaboration among firms. Two topics are often associated with collaboration in industrial clusters:

- Social capital: refers to the set of intangible factors that exist in a community, such as values, norms, attitudes, trust and networks that facilitate coordination and collaboration for the common good (Cohen and Prusak, 2001);

- Collective efficiency: competitive advantage gained through external economies and joint actions (Schmitz, 1995).

Some authors contend that concentrations of firms foster network formation, since companies can take advantage of the proximity to strengthen the bonds with local firms and establish new partnerships (Camarinha-Matos and Affsarmanesh, 2005). There is some empirical evidence in the literature linking social networks and the knowledge exchange among co-located firms, which in turn may facilitate innovation among companies (Morosini, 2004; Steiner and Hartmann, 2006). For example, Baptista and Swann (1998) found that the concentration of specialized workers of a given sector facilitate knowledge spillovers, which in turn may lead to increased levels of innovation. Steinle and Schiele (2002) argue that companies must interact with each other in order to benefit from locating within a cluster, which in turn requires a climate that stimulates cooperation and intensive knowledge exchange.

\subsection{Performance management in industrial clusters}

Performance management has been a central topic in organizational and operations management (Neely, 2005). This has led many authors to develop frameworks that assist companies in designing their performance measurement systems (PMS) (Neely, 1995; 2005; Kaplan, 1996; Kennerley, 2002; Radnor and Barnes, 2007). As pointed out by Neely (1998), a PMS can be used to four purposes: check current position, communicate performance, confirm priorities and compel progress. This reinforce the role of performance management in strategic issues, such as setting priorities, targets and deploying strategies by cascading down actions that will ultimately make the company achieve its planned objectives. Due to the apparent importance of performance management to individual organizations, many authors have tried to apply this theory to measure multi-firm relationships as supply chains (Chow et al., 1994), organizational networks (Camarinha-Matos and Affsarmanesh, 2007) and industrial clusters (Carpinetti et al., 2008).

Indeed, performance management in industrial clusters has drawn considerable attention from several authors and has been viewed as a basis for the management of a cluster (Sölvell et al. 2003; DTI, 2005; Gerolamo et al., 2008; Carpinetti et al., 2008). Furthermore, the use of numerical means to demonstrate the benefits of collaboration in organizational networks would motivate companies to collaborate more and establish new partnerships (Camarinha-Matos and Affsarmanesh, 2007). According to a report written to the English Department of Trade and Industry, measuring a cluster's performance may be useful to evaluate the appropriateness, effectiveness and efficiency of interventions (DTI, 2005). Collaboration, on its turn, can be viewed as a metric composed of three measurable dimensions: information sharing, decision synchronization and incentive alignment (Simatupang and Sridharan, 2005). It is thus clear that, for companies to collaborate with each other in joint initiatives, it becomes necessary a coordination mechanism that balances the interests and serves as a communication channel among the parties involved. This means communicating the status of ongoing activities and the impacts of joint initiatives, which should be done by means of performance measures.

There does not seem to be a sound approach or framework in the literature that fulfils the need of a performance management model to facilitate the conduction and assessment of collaborative initiatives in industrial clusters. There are though some contributions that try to fill this gap. Sölvell et al. (2003) developed the Cluster Initiative Performance Model (CIPM), in which the performance of a cluster initiative is measured in terms of innovation, international competitiveness, cluster growth, and achievement of goals. According 
to the authors, cluster's performance is ultimately affected by three elements: the social, political and economic setting within the nation; the objectives of the cluster initiative; and the processes by which the cluster initiative develops. Carpinetti et al. (2008) proposed a framework to design performance measurement systems for industrial clusters. The authors divided performance measures into four perspectives: economic and social results; company's performance; collective efficiency; and social capital. A similar contribution was made by Bortolotti and Amato Neto (2006), who developed a 6-dimension framework to characterize and evaluate industrial clusters. The six dimensions included in the framework were related to geographic, economic, institutional, social, technological and environmental aspects of the industrial cluster as a whole. The European Commission carried out seven case studies in networks from the automotive sector and proposed a five-step method to the management of networks (EC, 2001):

- Step 1 - Goal, potential and strategy: consists of drawing together the key stakeholders of the network;

- Step 2 - Starting the network: setting of rules between partners and preparation of the operational background;

- Step 3 - Implementation of the network: establishment of an appropriate information and communication platform to connect all network participants;

- Step 4 - Management of the network: management of the network activities by focusing on information and communication, training, innovative projects, internationalization, and marketing and advertising;

- Step 5 - Evaluation of the network: consists of auditing the network actions and gathering feedback from network members to continuously improve the management of the network;

An analogous contribution was made by Gerolamo et al. (2008), who developed a performance management model for industrial clusters and cooperation networks. Their model is divided into five steps:

- Step 1 - Identification of the stakeholders: the first step is to identify the stakeholders directly or indirectly related to the cluster activities (large enterprises, SMEs, local partners, local associations, the local chamber of commerce and industry, universities, public authorities, financial institutions and so forth;
- Step 2 - Strategic orientation and definition of objectives: formulation of a strategic plan that balances the interests of local companies as well as other interested parties, such as local authorities and the community.

- Step 3 - Implementation of improvement and innovation projects: based on the elements formulated in Steps 1 and 2, a series of joint initiatives should be developed to take advantage each partner's capabilities as well as to increase trust among companies;

- Step 4 - Performance evaluation and measurement: definition of a process to measure and evaluate the performance and impact of joint actions;

- Step 5 - Supporting infrastructure for the management process: establishment of the infrastructure necessary to support cooperation projects, such as a regional office or a regional development agency.

\subsection{Institutions for collaboration}

Besides the external economies that naturally emerge in agglomerations, companies my benefit greatly from local supporting institutions oriented towards satisfying specific needs of the cluster participants (Karaev et al., 2007). As pointed by Seliger et al. (2008), such institutions are vital for the coordination of joint actions and diffusion of specific knowledge inside the cluster. Schmitz and Nadvi (1999) contend that local agencies should mediate conflicts of interest that may arise between companies within the cluster. The existence of local coordination may differentiate a mere agglomeration of companies from a comprehensive local innovation system that aims to improve local competitiveness through joint actions and network formation (Gerolamo et al., 2008).

Several terms can be found in the literature to refer to these supporting institutions, such as cluster initiatives (Sölvell et al., 2003; Ketels and Sölvell, 2006), institutions for collaboration (Sölvell et al., 2003; 2008), industry associations (ITD, 2009), regional development agencies (Seliger et al., 2008) or institutional thickening (Andriani et al., 2005). In this paper we refer to local supporting institutions in clusters as institutions for collaboration (IFC).

These institutions may assume a variety of forms, such as private organizations, public agencies or industry associations. The literature reports a number of cases concerning institutions for collaboration (see some examples in Schmitz, 1998; Sölvell et al., 2003; Gerolamo et al., 2008). It seems that cultural 
issues, the type of business, the economic setting, and the existing social capital may influence the form of local IFCs. In spite of that, it seems to be consensus in the literature that regardless of the way the IFC comes about in a cluster, it plays a vital role in managing interactions, sharing of knowledge and in providing a cognitive framework for transforming information into useful knowledge (Audretsch and Lehmann, 2006; Steiner and Ploder, 2008).

As to the emergence of these institutions, Sölvell et al. (2003) argue that after a cluster's formation, the region tends to accumulate resources and commitment of its participants, which may culminate in the establishment of local IFCs. The authors describe IFCs as formal institutions maintained with fees paid by local firms that seek to balance the interests of the different actors involved with the industrial cluster. IFCs may act upon several issues by coordinating joint actions concerning quality of life, education, infrastructure (transportation, energy, and communication), tax regulation, export strategy, quality standards, research and training, and so forth (Sölvell, 2008; ITD, 2009).

\section{The performance and change management model}

The model described in this section aims to help IFCs in industrial clusters in the planning, implementation and evaluation of joint actions. One such institution may encompass representatives from the various cluster actors, such as the companies, the government, research centres, universities and so forth. Figure 2 shows the proposed model, which is divided into three dimensions - infrastructure, strategic planning and implementation and assessment. The model emphasizes the implementation of joint actions that seek to improve some aspect of the industrial cluster's performance. It does not necessarily mean that all companies in the cluster should be involved in every joint action supported by the institution, but rather that each joint action should benefit at least a subset of the local companies. The execution of these actions requires strong coordination, especially due to their collective nature. At this point, the support provided by institutions becomes crucial, since they can serve as mediators between the several parties involved in the joint action.

\subsection{Infrastructure}

The model in Figure 2 suggests that the IFC should identify the existing infrastructure prior to the definition and execution of joint actions. By identifying the local infrastructure, the institution will be able to put forth joint actions that optimize infrastructure utilization and improve existing facilities.

Local infrastructure can be analyzed at two major levels - institutional and regional. At the institutional level, the model points to the establishment of a statute to formalize its management hierarchy and the roles assigned to each member. A local office should also be set up with the management tools and information systems necessary for the institution to conduct its activities and manage joint actions. Additionally, a coordinator or a coordination team should be chosen to act directly upon the joint actions and innovation programs supported by the institutions. The role of

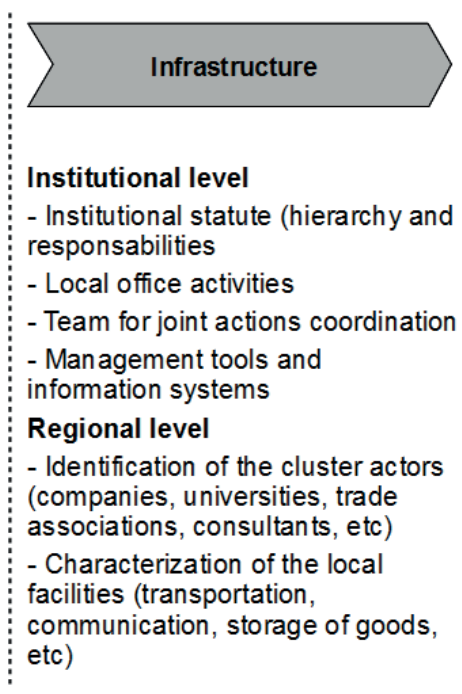

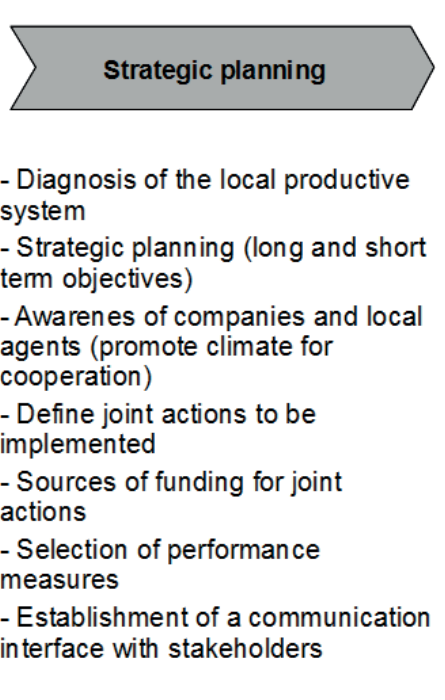

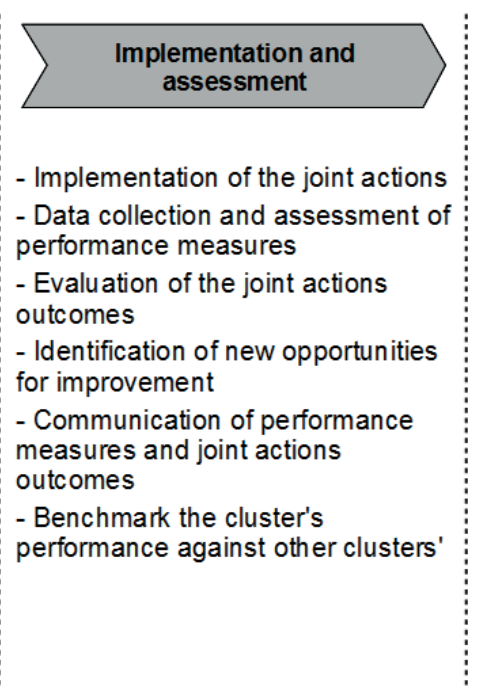

Figure 2. The three dimensions of the proposed model. 
this coordination body is to mediate the interests and assignments between the parties involved with a given joint action.

The infrastructure elements at the regional level refer to cluster actors and facilities that can contribute to the execution of joint actions. For example, cluster actors such as technical schools, specialized service providers and universities can provide specific knowledge to the coordination team and to the companies involved in a joint action. Besides these actors, the institution should identify the local facilities that could be exploited by local companies. Examples of such infrastructure elements are roads, railroads, warehouses, intermodal ports, communication lines, power supplies, sources of raw material and so forth. These need to be mapped by the institution so that actions can be taken, both to use and to improve the existing infrastructure.

\subsection{Strategic planning}

From the standpoint of individual firms, strategic planning is the process by which leaders formulate their vision of future and develop the procedures and operations to achieve such vision (Goodstein et al, 1993). In this sense, strategic planning can be viewed as a tool to help organizations set priorities and allocate resources to achieve them (Allison and Kaye, 2006). From the perspective of an institution promoting joint actions in industrial clusters, the main strategic objectives differ from the traditional profit and productivity objectives of regular organizations. The strategic objectives of an IFC should be related to the improvement of the various performance dimensions of the industrial cluster.

Hence, the objective of the second dimension of the model is to motivate the institution to formulate its strategic planning. However, the plurality of actors involved with the cluster raises several challenges to the formulation of short and long term goals that balance the desires of local businesses that often compete with each other. For that reason, joint actions need not necessarily involve all firms, but rather those whose goals match the purpose of the initiative being planned. The following sources can be used to inspire the formulation of joint actions:

- Needs of businesses: the institution may conduct a diagnosis of local businesses needs and devise joint actions based upon the needs common to certain groups of firms;

- Public policies: On the one hand, the institution may search for public policies that favour local economic activities and increase awareness of local firms about them. On the other hand, the institution may act as a representative of companies before the governmental agencies to suggest policies that would incentive the local economic activities;

- Existing infrastructure: the diagnosis conducted in the first dimension of the model can reveal opportunities with respect to the use and improvement of the local infrastructure. Moreover, joint actions may combine the skills of a subset of the actors in the cluster to promote innovation among businesses.

In order to formulate the strategic planning, the model also suggests that the institution should characterize the local productive system and identify ongoing joint actions, so that their goals can be reassessed for the next management cycle. With all this information in hand, the institution will be able to determine more appropriate short and long term goals and set out the joint actions to help achieve these goals. Later on, these actions will have to be deployed to all the parties involved to determine their roles and activities. The institution can refer to the hoshin kanri technique to this end (Akao, 2004). Finally, three additional aspects should be taken into account when formulating the institution's strategic planning:

- The sources of funding for implementing joint actions;

- The means by which the results of actions will be communicated to businesses and other stakeholders;

- The performance measures that need to be implemented to evaluate the results of actions in numerical terms.

\subsection{Implementation and assessment}

The third dimension of the model consists of implementing the items designed in the strategic plan.

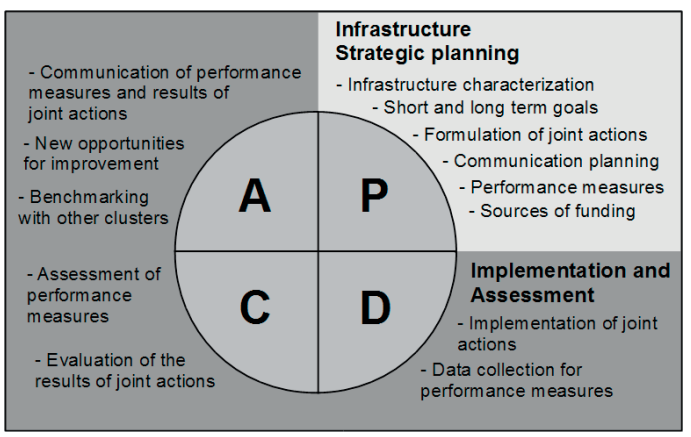

Figure 3. The proposed model and the PDCA cycle. 
In other words, the institution should execute the joint actions foreseen in the strategic plan and gather data to calculate performance measures as a means of assessing the impacts of such actions. It becomes now clear that the model is strongly influenced by continuous improvement principles and the PDCA (Plan, Do, Check and Act) cycle. Figure 3 illustrates this by associating the dimensions of the model with the phases of the PDCA cycle.

As depicted in Figure 3, the first two dimensions of the model correspond to the Plan phase of the PDCA cycle, during which the institution should characterize the local infrastructure, set short and long term objectives, devise the joint actions to be implemented and define the performance measurement system to be used in the remainder of the cycle. The third dimension of the model stretches across the Do, Check and Act phases of the PDCA cycle. During the Do phase, joint actions should be implemented as planned and data for performance measures should be collected. During the Check phase, performance measures and the results of joint actions need to be assessed in order to determine the degree to which the objectives have been achieved. The last phase of the PDCA cycle corresponds to the communication of performance and action results, benchmarking with other clusters and the identification of further opportunities for improvement.

\subsection{Model implementation}

The implementation of the proposed model will hardly occur at once. Instead, it is expected that institutions will develop some of the practices concurrently, regardless of the dimension to which they belong. It is thus pointless to devise a series of steps to implement the model, because each institution will choose different paths to implement it. It is however necessary to understand the dynamics of the model, that is the structure required so that continuous improvement may flow throughout the model. Figure 4 illustrates the dynamics of the model by dividing

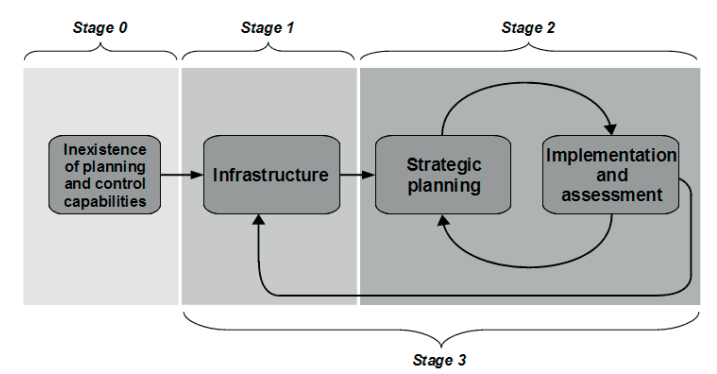

Figure 4. Dynamics between the dimensions of the model it into four stages, by which the institution should gradually implement and improve its management practices. The dynamics proposed in Figure 4 enables the institution to learn from experience and encourages continuous improvement of its planning, execution and assessment capabilities.

The stages in Figure 4 are associated with the operation of each dimension of the management model. Stage zero (S-0) is the initial stage of implementation and corresponds to an IFC that has no formal planning and control capabilities in place to manage joint actions. The first stage (S-1) encompasses the characterization of the regional infrastructure and the establishment of the management tools, information systems and supporting facilities to coordinate joint actions. The second stage (S-2) covers the strategic planning and the implementation and assessment dimensions. It does not regard both dimensions separately, but rather the closed planning, execution and assessment loop, which was depicted in Figure 3. Thus, when the institution reaches this stage, it will have successfully developed practices to formulate strategic plans, design performance measures, execute joint actions and assess its results and outcomes. Stage three (S-3) is achieved when the IFC has put in place a mature management system that fully covers the practices from the three dimensions of the model. At this stage the institution will have learned from experience and improved its managerial capabilities in a way that future joint actions will be better coordinated between the companies, the institution and other cluster actors. Additionally, the experience gained after several management cycles may teach the institution how to better choose and formulate joint actions that will ultimately meet the real needs of local companies and actors. These aspects together may increase the success rate of actions and hence increase trust between companies and the institution.

\subsection{Self-assessment tool}

As mentioned earlier, it is very unlikely that an IFC will implement the management model at once. Moreover, even though institutions may not be aware of the model proposed in this paper, many of them have already implemented managerial practices that satisfy some of the model requirements. It becomes thus necessary a tool to help such institutions evaluate their management practices in relation to those required by the model as a way to determine what areas need improvement. To this end, a set of requirements were devised to characterize each stage of the management model and organized as a 
diagnostic tool. Tables 1, 2 and 3 list the requirements and questions to evaluate each of the requirements from the stages S-1, S-2 and S-3, respectively.

Consistent with the stages in Figure 4, the questions in Table 1 are related to the characterization of the infrastructure at the regional and institutional levels. Table 2 puts forth questions to evaluate how the institution plans, executes and assesses joint actions, which is done by verifying the existence of strategic plans, performance measures, communication with stakeholders and benchmarking mechanisms. Finally, the questions in Table 3 address the effectiveness of the institution's management practices and the joint actions it has carried out.

The requirements and questions from Tables 1, 2 and 3 can be used as a self-assessment tool so that institutions can evaluate their management practices and determine to which extent they comply with the management model. This can be helpful in pointing areas for improvement in the management of IFCs. To this end, the institution should assign scores using integral numbers ranging from 0 to 10 to indicate the extent to which the requirement is met. The following reference scale can be used to help determine scores:

- 0 to 3 points: indicate that the institution has no adherence to the requirement or at best it has plans of meeting the requirement, but no effective results have been achieved yet;

- 4 to 6 points: the institution has conducted activities that indicate partial compliance with the requirement, that is the activities have been reasonably effective but still can be performed better;

- 7 to 10 points: the practices being carried out by the institution demonstrate high or total adherence to the requirement.

\section{Application of the self-assessment tool}

The tool described in the previous section was used to evaluate the management practices of three Brazilian industrial clusters against the proposed model. Table 4 lists the three clusters researched and the institutions in which the self-assessment tool was applied. The prevalent economic activity in the city of Sertaozinho (C1) is the production of equipment to the ethanol industry. There is in the city an above average concentration of metal-mechanic firms plus a number of companies that provide supporting services, such as automation and maintenance (SEBRAE, 2007). The self-assessment tool was applied in the APL Metaltec, which is an institution supported by the local association of entrepreneurs (CEISE) that aims to foster cooperation and improvement among local firms. The acronym APL is commonly used in Brazil to refer to industrial clusters. APL Metaltec was founded in 2008 and since then it has been promoting joint actions, especially among small and medium-sized firms, to promote continuous improvement and innovation. Examples of such initiatives are the free consulting services provided to SMEs to teach entrepreneurs about best management practices and the creation of a local seal of quality. Coordination of joint actions is done by a SEBRAE (Brazilian Micro and Small Business Support Service) consultant fully devoted to the promotion and management of joint actions.

The city of Arapongas (C2) is renowned by its high concentration of furniture producers. The cluster covers also the surrounding cities of Apucarana, Cambe, Rolandia and Sabaudia, totalling 545 firms and about 12,000 employees (IPARDES, 2006a). The Furniture Industry Association of Arapongas (SIMA) started off in 2005 the Furniture APL of Arapongas as a side project to support and coordinate some joint actions that were being conducted at that time. The

Table 1. Requirements for Stage 1.

\begin{tabular}{|c|c|}
\hline Requirement & Question \\
\hline R1 - Establishment of the local office & Does the institution have a local office that allows its operation? \\
\hline $\begin{array}{l}\mathrm{R} 2 \text { - Management tools and } \\
\text { information systems }\end{array}$ & $\begin{array}{l}\text { Are there appropriate management tools and information systems in place to } \\
\text { assist the institution in its operation and in the coordination of joint actions? }\end{array}$ \\
\hline R3 - Coordination & $\begin{array}{l}\text { Does the institution have a coordinator or a coordination team to manage joint } \\
\text { actions and innovation programs? }\end{array}$ \\
\hline R5 - Identification of the cluster actors & Have the actors involved with the cluster been formally identified? \\
\hline
\end{tabular}


Table 2. Requirements for Stage 2.

\begin{tabular}{|c|c|}
\hline Requirement & Question \\
\hline $\begin{array}{l}\text { R6 - Characterization of the local } \\
\text { productive system }\end{array}$ & Has the institution carried out a diagnosis of the local productive system? \\
\hline $\begin{array}{l}\text { R7 - Awareness of local companies } \\
\text { and other local actors }\end{array}$ & $\begin{array}{l}\text { How effective has the work of the institution been towards the awareness of } \\
\text { companies and other local actors with respect to collaboration as a means of } \\
\text { improvement and innovation? }\end{array}$ \\
\hline R8 - Formulation of the strategic plan & $\begin{array}{l}\text { Does the institution periodically formulate its strategic plan with short and long } \\
\text { term objectives that aim to improve the cluster's performance as a whole? }\end{array}$ \\
\hline R9 - Formulation of joint actions & $\begin{array}{l}\text { Are joint actions derived from the strategic plan and appropriately formulated? } \\
\text { (that is with an execution team, determination of responsibilities, associated } \\
\text { performance measures, sources of funding and the like) }\end{array}$ \\
\hline R10 - Existence of a PMS & $\begin{array}{l}\text { Is there a PMS in place that covers all the performance dimensions of the } \\
\text { cluster and that enables the institution to assess the impacts of joint actions? }\end{array}$ \\
\hline R11 - Assessment of joint actions & $\begin{array}{l}\text { Does the institution periodically assess the results of joint actions as a way to: } \\
\text { (i) determine the level of compliance with predetermined goals, (ii) readjust the } \\
\text { plan if necessary or (iii) identify new opportunities for improvement? }\end{array}$ \\
\hline R12 - Performance communication & $\begin{array}{l}\text { Are the results of joint actions and performance measures communicated to all } \\
\text { cluster stakeholders? }\end{array}$ \\
\hline R13 - Benchmarking & $\begin{array}{l}\text { Has the institution implemented mechanisms to benchmark its performance } \\
\text { measures and practices against those from other industrial clusters? }\end{array}$ \\
\hline
\end{tabular}

coordinator and vice coordinator of the initiatives are local entrepreneurs who dedicate part of their time to the management of the cluster's joint actions. They operate from within SIMA by using its infrastructure to promote meetings among companies and seminars about subjects of interest to local firms. Among the ongoing joint actions are the annual furniture trade fair, business missions to international fairs as a way of bringing new ideas to local designers, the construction of a quality lab to measure the quality of local products as well as courses to improve local managers' capabilities.

The information and communication technology (ICT) cluster found in the city of Londrina (C3) was identified by IPARDES (2006b) and comprises software developers, automation firms and a range of other ICT service providers. According to the coordinator of the ICT APL of Londrina, the city has approximately 140 ICT companies, among which 60 have signed the participation agreement so far. The ICT APL of Londrina was started off in 2006 as a joint initiative of local entrepreneurs and the state government. Joint actions are managed by a coordinator, a vice coordinator and a secretary, who are also company owners in the city. They dedicate part of their time to hold meetings with local companies in order to identify their needs and suggest actions that should be taken to improve competitiveness and performance of local firms. Noteworthy joint actions are the identification of

Table 3. Requirements for Stage 3.

\begin{tabular}{ll}
\hline \multicolumn{1}{c}{ Requirement } & \multicolumn{1}{c}{ Question } \\
\hline R14 - Existence of a mature PMS & $\begin{array}{l}\text { Is there a stable and mature PMS with historical data stored for at least two } \\
\text { years? }\end{array}$ \\
R15 - Learning from experience & $\begin{array}{l}\text { Has the institution learned from experience with past joint actions so that the } \\
\text { formulation and implementation of new actions that involve local companies } \\
\text { and actors is facilitated? }\end{array}$ \\
R16 - Long term initiatives & $\begin{array}{l}\text { Has the institution formulated and conducted long term initiatives that aim to } \\
\text { improve local infrastructure, both at the regional and institutional levels? }\end{array}$ \\
R17 - Involvement of small, medium & $\begin{array}{l}\text { Have the initiatives started off by the institution drawn interest from small, } \\
\text { medium and large firms? }\end{array}$ \\
R18 - Impact on performance & $\begin{array}{l}\text { Have the joint actions conducted by the institution been successful in improving } \\
\text { the overall cluster's performance? }\end{array}$ \\
\hline
\end{tabular}


Table 4. Description of the industrial clusters researched.

\begin{tabular}{cccl}
\hline Industrial cluster & Economic sector & Institution re-searched & \multicolumn{1}{c}{ Type of coordination } \\
\hline $\begin{array}{c}\text { Sertaozinho } \\
\text { (C1) }\end{array}$ & Metal-mechanic industry & $\begin{array}{c}\text { CEISE and APL } \\
\text { Metaltec }\end{array}$ & $\begin{array}{l}\text { The coordinator is a full-time SEBRAE } \\
\text { consultant }\end{array}$ \\
$\begin{array}{c}\text { Arapongas } \\
\text { (C2) }\end{array}$ & Furniture producers & $\begin{array}{c}\text { SIMA and Furniture APL } \\
\text { of Arapongas }\end{array}$ & $\begin{array}{l}\text { The coordinator and the vice-coordinator } \\
\text { are company owners in the city }\end{array}$ \\
$\begin{array}{c}\text { Londrina } \\
\text { (C3) }\end{array}$ & Information and & ICT APL of Londrina & $\begin{array}{l}\text { The coordinator and the vice-coordinator } \\
\text { are company owners in the city }\end{array}$ \\
\hline
\end{tabular}

common training needs to specialize local workforce and the establishment of a local business centre that can be used both for joint purchasing and for selling local products and services to private and public organizations.

The self-assessment was conducted with assistance of the researchers, who used the questions from Table 1, 2 and 3 to interview the coordinators of each institution. The responses given to each question were transcribed to determine the level of compliance to each of the requirements. Table 5 presents the scores obtained after the interviews.

The scores in each requirement, as shown in Table 5 , were grouped to determine the average score in relation to the three implementation stages. These results are shown in Table 6.

\section{Discussion}

The use of three cases of industrial clusters enabled not only an evaluation of the management practices at the cluster level, but also a cross-case investigation of the practices to establish similarities and differences between them. The line graph in Figure 5 shows the scores for each of the 18 requirements in the three clusters researched and the mean score for each requirement.

It is visually noticeable in the line graph that the lines for each cluster tend to follow the mean line, which indicates little variation in many of the requirements. There is though great variety between the scores of some other requirements. A better measure to quantify this variation is the column Range in Table 5. A great range between the scores of a certain requirement indicates that there is significant difference between the management practices adopted in the three cases. The average range observed is 2,67 . We will thus consider that a requirement has little variation in the cross-case analysis if its range is lower or equal to 2. Great variation in a requirement is characterized by a range equal or greater than 4 . Because scores were defined in integer numbers, we defined an intermediate classification of variability when the range is equal to 3 . By using these criteria, the requirements R5, R6, R9, R10, R11, R12, R13 and $\mathrm{R} 18$ showed low variation, whereas the requirements R4, R8, R15, R16 and R17 showed high variation between the cases. Requirements R1, R2, R3 and R7 fell in the intermediate group.

The observation of the means obtained for each requirement allows the determination of the overall level of compliance with the practices specified in the management model. The scale described in Section 4.5 was used to classify and discuss the means observed. However, relying solely on the means or on the ranges may lead to wrong conclusions. For example, if a given requirement showed a low mean, it does not necessarily mean that all the three clusters did not perform the practices specified for that requirement, because there may be high variability between the cases, which is indicated by the range. In order to reach more precise conclusions with respect to each requirement, it is necessary to analyze

Table 5. Scores obtained in eah cluster.

\begin{tabular}{cccccc}
\hline & \multicolumn{3}{c}{ Scores (0 to 10) } & & \\
\cline { 2 - 4 } Req. & C1 & C2 & C3 & Avg. & Range \\
\hline R1 & 7 & 10 & 7 & 8,0 & 3 \\
R2 & 5 & 5 & 2 & 4,0 & 3 \\
R3 & 10 & 7 & 7 & 8,0 & 3 \\
R4 & 5 & 9 & 6 & 6,7 & 4 \\
R5 & 9 & 9 & 10 & 9,3 & 1 \\
R6 & 6 & 5 & 7 & 6,0 & 2 \\
R7 & 6 & 9 & 6 & 7,0 & 3 \\
R8 & 3 & 6 & 10 & 6,3 & 7 \\
R9 & 6 & 7 & 6 & 6,3 & 1 \\
R10 & 1 & 3 & 2 & 2,0 & 2 \\
R11 & 4 & 4 & 5 & 4,3 & 1 \\
R12 & 5 & 6 & 5 & 5,3 & 1 \\
R13 & 1 & 1 & 3 & 1,7 & 2 \\
R14 & 0 & 0 & 0 & 0,0 & 0 \\
R15 & 3 & 6 & 7 & 5,3 & 4 \\
R16 & 3 & 6 & 7 & 5,3 & 4 \\
R17 & 3 & 5 & 8 & 5,3 & 5 \\
R18 & 3 & 5 & 5 & 4,3 & 2 \\
\hline
\end{tabular}




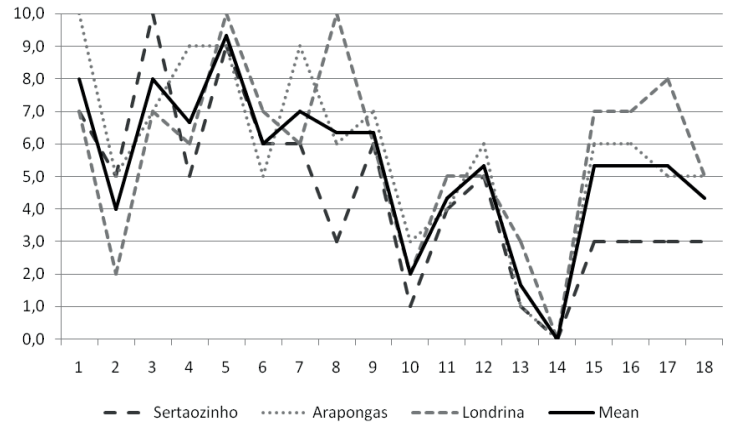

Figure 5. Line graph with scores in each case

both their means and ranges. Table 7 classifies the requirements according to their means and ranges, in which the rows represent the categories for the mean adapted to real numbers (see Section 4.5) and the columns represent the three classifications for the range, as previously described in this section.

One important conclusion that can be drawn from Table 7 is that the scores did not differ significantly in 9 out of the 18 requirements (see first column in Table 7). Nevertheless, only R5 had a mean score above 7, which indicates that the identification of the actors involved with the cluster is a common practice in the three clusters researched. The diagnosis of the local productive system (R6), the formulation (R9) and evaluation (R11) of joint actions, performance communication (R12) and the impact of joint actions (R18) achieved a partial level of compliance. In such cases, either the management practices were still being implemented or they still needed improvement. For example, all the clusters had some qualitative mechanism to evaluate the results of joint actions (R11), which was done mainly in meetings with the institution staff and companies' representatives, but none had performance measures to quantify the efficiency and effectiveness of the joint action.

It is seemingly a consequence of the inexistence of a formal PMS in the three clusters, which is demonstrated by the low scores recorded in R10 and R14. Besides, the requirement R13 achieved

Table 6. Scores grouped according to the implementation stages.

\begin{tabular}{lccccccc}
\hline & \multicolumn{2}{c}{ C1 } & & \multicolumn{2}{c}{ C2 } & & \multicolumn{2}{c}{ C3 } \\
\cline { 2 - 3 } \cline { 8 - 9 } Stage & Score & Avg. & Score & Avg. & Score & Avg. \\
\hline S-1 & 36 & 7,20 & 40 & 8,00 & & 32 & 6,40 \\
S-2 & 32 & 4,00 & 41 & 5,13 & & 41 & 5,13 \\
S-3 & 12 & 2,40 & 22 & 4,40 & & 27 & 5,40 \\
Overall & 80 & 4,44 & 103 & 5,72 & & 103 & 5,72 \\
\hline
\end{tabular}

low scores in all clusters because there were no benchmarking mechanisms in place to assist the institution in comparing the cluster's performance with that of other clusters. The ICT cluster of Londrina was the only one that was planning to take part in a SEBRAE benchmarking initiative that seeks to compare the performance of companies according to the criteria from the Brazilian national quality award. Such initiative, however, is still at an early stage of implementation and concrete results have not been observed as of the time of this research.

The establishment of a local office (R1), the existence of a coordination team (R3) and the awareness of companies (R7) also seem to be common practices, though the observed range for these requirements was equal to 3 . In fact, the scores to R1 and R3 were equal or greater than 7 in the three clusters, and the range equalled 3 because one of the clusters scored 10 in these requirements. As for R7, Londrina and Sertaozinho scored below 7 because they were facing difficulties in formulating joint actions that draw the attention from small and large companies at the same time. In the case of Londrina, the cluster coordinator reported that many companies have not realized the benefits of taking part in the cluster initiatives regardless of their size, which partly explains why so many companies do not participate in the meetings periodically held in the institution.

Among the requirements with range greater than 3 , the formulation of strategic plans (R8) and the involvement of small and large companies (R17) were the ones that most differed in the cross-case analysis. The cluster of Londrina has steadily formulated strategic plans since 2006, whilst in Sertaozinho a formal strategic plan has never been written. Arapongas obtained an intermediate score because the practice was discontinued in 2009 to be resumed only in 2011. As for the requirement R17, Londrina achieved the highest score because the institution has successfully carried out initiatives that benefit companies regardless of their sizes, even though many of the local companies have not participated in these initiatives. The cluster of Arapongas, on its

Table 7. Requirements classified according to the means and ranges observed.

\begin{tabular}{lccc}
\hline & $\mathbf{R} \leq \mathbf{2}$ & $\mathbf{R}=\mathbf{3}$ & $\mathbf{R} \geq \mathbf{4}$ \\
\hline Mean $\leq$ 3 & R10, R13, R14 & - & - \\
3 $<$ Mean $<7$ & R6, R9, R11, & R2 & R4, R8, R15, \\
& R12, R18 & & R16, R17 \\
Mean $\geq 7$ & R5 & R1, R3, R7 & - \\
\hline
\end{tabular}


turn, reported that large companies are participating in the initiatives and meetings, though they act as observers rather than proactive agents.

Another important analysis that can be made concerns the average scores obtained by grouping the requirements according to the implementation stages. The line graph in Figure 6 was based on the data from Table 6. It is apparent in this line graph that the best scores were obtained in the first implementation stage. This is an indication that the clusters researched have established their local offices, coordination teams, and have identified the local infrastructure. A considerable drop can be noted in the second stage, which is caused mainly by the requirements R10, R11 and R13. This shows that designing performance measures, assessing the results of joint actions and establishing benchmarking mechanisms are still challenges in all the clusters.

With exception of Londrina, the lowest scores were observed in the third implementation stage. It is apparently a consequence of the nature of this stage, whose requirements demand that the management practices implemented in S-1 and S-2 become more mature and effective. Moreover, in order to achieve the third stage the cluster needs to learn from experience with past initiatives. This means that new joint actions should not only be well managed, but also that they should encompass the real interests of the parties involved so that their performance is impacted positively. A hypothesis derived from this reasoning is that an industrial cluster can achieve high scores in S-3 only after several iterations of $\mathrm{S}-2$, which is the continuous improvement cycle from Figure 3.

\section{Conclusions}

Institutions for collaboration in industrial clusters have played a vital role in improving the capabilities of local companies and in carrying out joint actions that extend the benefits of agglomeration beyond external economies. This was the motivation of this research, which aimed to contribute to the body of knowledge on industrial clusters by putting forth a performance and change management model to guide IFCs in the planning, implementation and assessment of joint actions. The model was divided into three dimensions - infrastructure; strategic planning; and implementation and assessment. To each of these dimensions, a number of management practices were associated. Based on this model, three

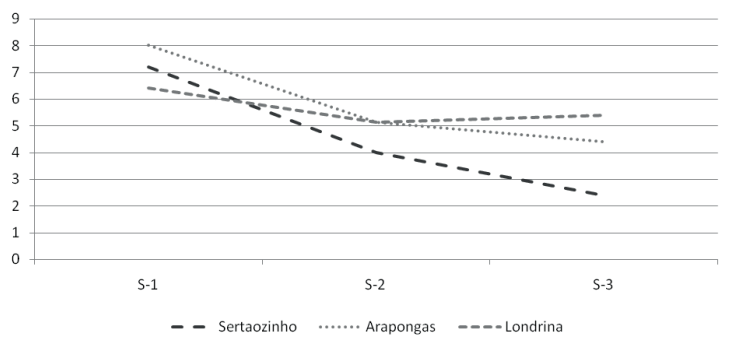

Figure 6. Compliance to the requirements according to the implementation stages.

implementation stages were identified, which served as ground to the formulation of a self-assessment tool that help the cluster determine its level of compliance with the proposed management model.

The tool was used in three industrial clusters to evaluate their management practices according to the model, which led to important insights and findings. First, the highest scores were observed in the first implementation stage (S-1), which is strongly related to the infrastructure dimension of the model. This is an indication that the clusters have not faced great barriers in establishing the infrastructure at the institutional level and identifying the local infrastructure and actors at the regional level. As for the strategic planning, some positive practices could be found in all the three clusters, though they have not been able to design performance measures to assess the results of joint actions in numerical terms. This may prevent future joint actions from drawing more interest of local companies, mainly because companies will not be able to measure precisely the benefits of taking part in such actions. Additionally, the inexistence of a performance measurement system hinders the benchmarking with other industrial clusters. Based on the scores obtained by each cluster, it becomes apparent that issues related to performance measurement prevented them from scoring better in S-3, since this stage requires that the institution establishes more mature management practices to plan, implement and assess joint actions.

Although the findings of this paper cannot be extended to all industrial clusters, they serve as empirical evidence that, in general, measuring the benefits of joint actions numerically is not a common practice yet. Future research on IFCs should seek ways to overcome the barriers to performance measurement, strategic planning, and the assessment of joint actions, since no widely accepted solutions for these issues have been proposed so far. 
Acknowledgements: This should always be a run-in heading and not a section or subsection heading. It should not be assigned a number. The acknowledgements may include reference to grants or supports received in relation to the work presented in the paper.

\section{References}

Akao, Y. (2004). Hoshin Kanri: Policy deployment for successful TQM. New York: Productivity Press.

Allison, M., \& Kaye, J. (2005). Strategic planning for non-profit organizations: a practical guide and workbook. New Jersey: John Wiley \& Sons.

Andriani, P., Jones, C., Perkmann, M., Propris, L., Sena, V., Delbridge, R., Möslein, K. M., \& Neely, A. (2005). Challenging clusters - the prospects and pitfalls of clustering for innovation and economic development. Summary Report from an AIM Management Research Forum in Cooperation with the Welsh Economy Research Unit, Advanced Institute of Management Research, June.

Audretsch, D., \& Lehmann, E. (2006). The role of clusters in knowledge creation and diffusion: an institutional perspective, in Asheim, B., Cooke, P., \& Martin, R. (eds). Clusters and Regional Development: Critical Reflections and Explorations, (pp. 188-198). Abingdon: Routledge.

Baptista, R., \& Swann, P. (1998). Do firms in clusters innovate more? Research Policy, 27(1), 535-540.

Bititci, U., Martinez, V., Albores, P., \& Parung, J. (2004). Creating and managing value in collaborative networks. International Journal of Physical Distribution and Logistics Management, 34(3/4), 251-268. doi:10.1108/09600030410533574

Bortolotti, F., Amato Neto, J. (2006). Development of a set of matrices for the evaluation and classification of regional clusters, in: Proceedings of the Euroma Conference, Glasgow, Scotland.

Brazilian Micro and Small Business Support Service - SEBRAE (2007). Perfil econômico municipal. http://www.sebraesp.com.br/ conhecendo_mpe/setoriais_regionais/perfil_economico

Camarinha-Matos, L., \& Afsarmanesh, H. (2005). Collaborative networks: a new scientific discipline. Journal of intelligent manufacturing, 16(1), 439-452. doi:10.1007/s10845-005-1656-3

Camarinha-Matos, L., \& Afsarmanesh, H. (2007). Performance indicators for collaborative networks based on collaboration benefits. Production Planning and Control, 18(7), 592-609. doi:10.1080/09537280701546880

Capó-Vicedo, J., Expósito-Langa, M., \& Molina-Morales, F. X. (2008). Improving SME competitiveness reinforcing interorganisational networks in industrial clusters. International Entrepreneurship and Management Journal, 4(2), 147-169. doi:10.1007/s11365-0070059-7

Carpinetti, L., Cardoza, E., \& Gerolamo, M. (2008). A measurement system for managing performance of industrial clusters: A conceptual model and research cases. International Journal of Productivity and Performance Management, 57(5), 405-419. doi:10.1108/17410400810881854

Chow, D., Heaver, T., \& Henriksson, L. (1994). Logistics Performance: Definition and Measurement. International Journal of Physical Distribution \& Logistics Management, 24(1), 17-28. doi:10.1108/09600039410055981

Cohen, D., \& Prusak, L. (2001). In Good Company: How Social Capital Makes Organizations Work. Boston: Harvard Business School Press.

Cortright, J. (2006). Making Sense of Clusters: Regional Competitiveness and Economic Development. Washington: The Brookings Institution.

English Department of Trade and Industry - DTI (2005). A Practical Guide to Cluster Development: Report to the Department of Trade and Industry and the English RDAs by Ecotec Research \& Consulting.

European Commission - EC (2001). Methodology for regional and transnational clusters: learning with European best practices - promotion of entrepreneurship and SMEs. Enterprise Directorate General, Promotion of Entrepreneurship and SMEs, Business Co-operation and Community Business Support Network Development, March.

Gerolamo, M., Carpinetti, L., Seliger, G., \& Galdamez, E. (2008). Performance management of regional clusters and SME cooperation networks. International Journal of Business Excellence, 1(4), 457-483. doi:10.1504/JJBEX.2008.018844

Goodstein, L., Nolan, T., \& Pfeiffer, J. (1993). Applied strategic planning: how to develop a plan that really works. New York: McGraw-Hill.

Institute for Economic and Social Development of Paraná - IPARDES (2006a). Arranjo produtivo local de móveis de Arapongas - Nota técnica, Curitiba, Brasil.

Institute for Economic and Social Development of Paraná - IPARDES (2006b). Arranjo produtivo local de software de Londrina - Estudo de caso, Curitiba, Brasil.

International Trade Department - ITD (2009). Clusters for competitiveness - a practical guide \& policy implications for developing cluster initiatives. The World Bank.

Kaplan, R., \& Norton, D. (1996). The Balanced Scorecard: Translating Strategy into Action. Boston: Harvard Business School Press. 
Karaev, A., Koh, S., \& Szamosi, L. (2007) The cluster approach and SME competitiveness: a review. Journal of Manufacturing Technology Management, 18(7), 818-835. doi:10.1108/17410380710817273

Kennerley, M., \& Neely, A. (2002). A framework of the factors affecting the evolution of performance measurement systems. International Journal of Operations and Production Management, 22(11), 1222-1245. doi:10.1108/01443570210450293

Ketels, C., \& Sölvel, Ö. (2006). Clusters in the EU-10 new member countries. Europe Innova Cluster Mapping.

Krugman, P. (1991). Geography and Trade. Cambridge: MIT Press.

Ministry of Development, Industry and Foreign Trade - MDIC (2010). Arranjos produtivos locais. http://www2.desenvolvimento.gov.br/sitio/ sdp/proAcao/arrProLocais/arrProLocais.php

Morosini, P. (2004). Industrial Clusters, Knowledge Integration and Performance. World Development, 32(2), 305-326. doi:10.1016/j. worlddev.2002.12.001

Mytelka, L., \& Farinelli, F. (2000). Local clusters, innovation systems and sustained competitiveness, Discussion Paper, United Nations University, The Netherlands.

Neely, A., Gregory, M., \& Platts, K. (1995). Performance measurement system design: a literature review and research agenda. International Journal of Operations and production Management, 15(4), 80-116. doi:10.1108/01443579510083622

Neely, A. (1998). Measuring business performance. London: The Economist.

Neely, A. (2005). The evolution of performance measurement research - developments in the last decade and a research agenda for the next. International Journal of Operations \& Production Management, 25(12), 1264-1277. doi:10.1108/01443570510633648

Plummer, P., \& Taylor, M. (2001). Theories of local economic growth (part 1): concepts, models, and measurement. Environment and Planning, 33(2), 219-236. doi:10.1068/a339a

Porter, M. (1998). Clusters and the new economics of competition. Harvard Business Review, nov-dec, 77-90.

Radnor, Z., \& Barnes, D. (2007). Historical analysis of performance measurement and management in operations management. International Journal of Productivity and Performance Management, 56(5/6), 384-396. doi:10.1108/17410400710757105

Schmitz, H. (1995). Collective Efficiency: Growth path for small-scale Industry. Journal of Development Studies, 31(4), 529-566. doi:10.1080/00220389508422377

Schmitz, H. (1998). Responding to global competitive pressure: local cooperation and upgrading in the Sinos Valey, Brazil. Institute of Development Studies, Working Paper, 82.

Schmitz, H., \& Nadvi, K. (1999). Clustering and industrialization: introduction. World Development, 27(9), 1503-1514. doi:10.1016/S0305$750 \times(99) 00072-8$

Seliger, G., Carpinetti, L., \& Gerolamo, M. (2008). Promoting innovative clusters and cooperation networks: the European Commission observatories of SMEs and the context of Berlin-Brandenburg. International Journal of Networking and Virtual Organizations, 5(2), 204223. doi:10.1504/IJNV0.2008.017011

Simatupang, T., \& Sridharan, R. (2005). The collaboration index: a measure for supply chain collaboration. International Journal of Physical Distribution and Logistics Management, 35(1), 44-62. doi:10.1108/09600030510577421

Sölvell, Ö., Lindqvist, G., \& Ketels, C. (2003). The Cluster Initiative Greenbook. Stockholm: Bromma Tryck AB.

Sölvell, Ö. (2008). Clusters - balancing evolutionary and constructive forces. Stockholm: Ivory Tower Publishers.

Steiner, M., \& Hartmann, C. (2006). Organizational Learning in Clusters: A Case Study on Material and Immaterial Dimensions of Cooperation. Regional Studies, 40(5), 493-506. doi:10.1080/00343400600757494

Steiner, M., \& Ploder, M. (2008). Structure and strategy within heterogeneity: multiple dimensions of regional networking. Regional Studies, 42(6), 793-815. doi:10.1080/00343400701861310

Steinle, C., \& Schiele, H. (2002). When do industries cluster? A proposal on how to assess an industry's propensity concentrate at a single region or nation. Research policy, 31(6), 849-858. doi:10.1016/S0048-7333(01)00151-2

United Nations Industrial Development Organization - UNIDO (2001). Development of clusters and networks of SMEs, Vienna. 